Article

\title{
Design of a Bidirectional Energy Storage System for a Vanadium Redox Flow Battery in a Microgrid with SOC Estimation
}

\author{
Qingwu Gong and Jiazhi Lei * \\ School of Electrical Engineering, Wuhan University, Wuhan 430072, China; qwgong@whu.edu.cn \\ * Correspondence: leijiazhi@126.com; Tel.: +86-27-6877-2281 \\ Academic Editor: Tomonobu Senjyu \\ Received: 1 December 2016; Accepted: 14 March 2017; Published: 17 March 2017
}

\begin{abstract}
This paper used a Vanadium Redox flow Battery (VRB) as the storage battery and designed a two-stage topology of a VRB energy storage system in which a phase-shifted full bridge dc-dc converter and three-phase inverter were used, considering the low terminal voltage of the VRB. Following this, a model of the VRB was simplified, according to the operational characteristics of the VRB in this designed topology of a VRB energy storage system (ESS). By using the simplified equivalent model of the VRB, the control parameters of the ESS were designed. For effectively estimating the state of charge (SOC) of the VRB, a traditional method for providing the SOC estimation was simplified, and a simple and effective SOC estimation method was proposed in this paper. Finally, to illustrate the proper design of the VRB ESS and the proposed SOC estimation method, a corresponding simulation was designed by Simulink. The test results have demonstrated that this proposed SOC estimation method is feasible and effective for indicating the SOC of a VRB and the proper design of this VRB ESS is very reasonable for VRB applications.
\end{abstract}

Keywords: vanadium redox flow battery; energy storage system; SOC estimation; simplified equivalent model; parameter design

\section{Introduction}

An energy storage system (ESS) which can be used for peaking regulation in power plants or power stations, and which can be used as an energy storage device in new energy generation systems, has the potential to be very widely applied in power systems [1,2]. As an effective technique for enhancing integrating intermittent renewable energy into a power grid, battery energy storage has become one of the focal points of development, due to its unique performance [3].

A Vanadium Redox flow Battery (VRB), as a new storage battery, can be used as the energy storage unit in an ESS. In an ESS, the topology should consider the terminal voltage of the VRB. In addition, to design reasonable control parameters for an ESS, the model of a VRB should be simplified, which has not been included in previous research. The parameter of the state of charge (SOC), as one of the most important parameters of a VRB, represents the residual capacity of a VRB and is the key parameter to regulate or control the operating states of an ESS. Hence, the effective estimation of the SOC is very significant.

Recently, many researchers have concentrated on the design of a VRB energy storage system [4-10]. In $[4,5]$, a control strategy of an ESS, based on a bidirectional DC-DC converter for a novel stand-alone photovoltaic power system, was proposed. But, this ESS was connected to a DC bus, without considering the power flow between the energy storage battery and the AC grid, resulting in great limitations for the energy storage system. The ESS in [6,7] is composed of a three-phase grid-connected inverter and a power frequency transformer, in which reasonable control of the battery is very difficult 
to realize. In [8-10], a large scale ESS based on various energy storage units, in which a buck-boost converter is used, was proposed. However, the ESS topologies involved in these papers are not suitable for a VRB ESS, considering the low terminal voltage of a VRB. The phase-shifted full bridge dc-dc converter in [11-13] uses a low current and voltage for the power switch and is very suitable for a VRB ESS.

In the designed topology of a VRB energy storage system, there are various VRB models which have been developed for dealing with the control parameters of an ESS. However, most of these are based on how to establish an objective function of a VRB for describing the performance characterization of a VRB. In [14-18], an equivalent model of a VRB was comprehensively introduced, to obtain the operational characteristics of a VRB. In $[19,20]$, a comprehensive equivalent circuit model of a VRB was presented for system level analysis, in which the concentration over potential is modeled as a function of flow rate, in an order to determine determine an appropriate variable flow rate. But these proposed models of VRBs are not suitable for the design of the control parameters in a VRB energy storage system, considering the complexity of these models.

Moreover, the SOC estimation has become an important research topic for VRBs in ESSs. In [21-24], different effective management methods based on the parameter of the SOC of the battery were introduced, but the SOC estimation method of a VRB is not included. In the past decade, several methods have been proposed for SOC estimation in many battery applications [25-28]. A very common method for estimating the SOC of a redox flow cell is the installation of an open-circuit cell at the entry or exit ports of the electrolytes in the cell stack. By using the Nernst equation, the SOC can be readily obtained from the measured open circuit voltage (OCV) [25]. However, as the OCV gives an overall value of the two half-cells which are assumed to be balanced, this procedure does not accurately indicate the SOC of a VRB. In [26], for the estimation of Zero Emission Battery Research Activities (ZEBRA) battery, a hybrid neural model is proposed considering the state of health and the discharge efficiency parameters. In [27], two state-of-charge monitoring methods and their use in the VRB are investigated. In [28], the SOC estimation of VRBs was realized by an extended Kalman filter (EKF) method. However, these SOC estimation methods make stack configuration more complex as one open flow cell needs to be spared for each stack and additional voltage sensors need to be installed. Therefore, all of these methods for SOC estimations are too complex and are not suitable for application.

Considering these points, this paper firstly designs a two-stage topology of a VRB energy storage system considering the low terminal voltage of the VRB, in which a phase-shifted full bridge dc-dc converter and three-phase inverter are used and the bidirectional power flowing between the energy storage battery and AC grid is achieved. Following this, the model of a VRB is simplified according to the operational characteristics of the VRB in this proposed topology of a VRB ESS and the control parameters of the ESS are designed. For effectively managing the control center of the microgrid (MG), a traditional method for SOC estimation is simplified, and a simple and effective SOC estimation method is established. Finally, the feasibility and effectiveness of the proposed SOC estimation method are verified by the designed VRB ESS, and the test results demonstrate that the proposed SOC estimation method is reasonable for indicating the SOC of a VRB and that the proper design of the VRB ESS is very reasonable for VRB applications.

\section{Topology of a VRB ESS in a Microgrid}

With the increasing depletion and fluctuation of fossil fuel prices, residential and industrial pollution, etc, energy storage system can be used as a sorted renewable energy system for clean energy [29]. Figure 1 shows the designed topology of a VRB energy storage system in a microgrid. In Figure 1, the structure of a microgrid (MG) is shown. Photovoltaic generation units and wind generation units (WPG) are respectively connected to the AC grid by power electronic devices. Due to the randomness of the PV and WPG, it is essential to configure the VRB ESS, to maintain the power balance in the MG. The control center of the MG gathers the electrical quantities of all of the converters and operates the power flow of the MG by controlling these converters. It should be noted that the 
SOC of the VRB is one of the most important parameters for the control center of the MG to control these converters. Therefore, the SOC of the VRB is effectively estimated in this paper.

The most important part of a battery energy storage system is the power conversion system (PCS), which is actually a voltage source inverter. Through the use of a power conversion system, bidirectional power flow is achieved between the energy storage battery and the AC grid. Discharging and charging management of the VRB, and load power tracking of the AC grid, can also be realized by controlling a PCS.

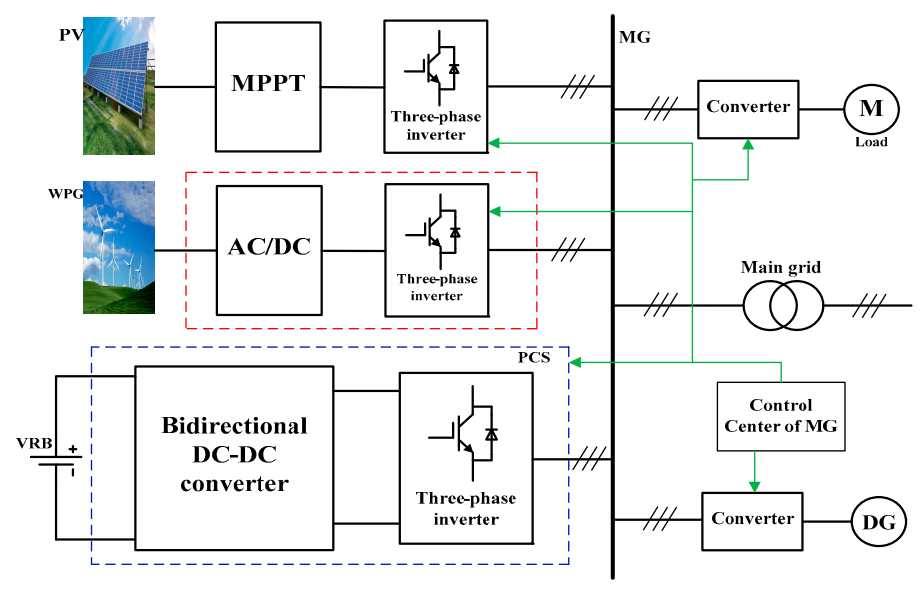

Figure 1. Topology of the VRB energy storage system in the microgrid.

In this paper, a $5 \mathrm{~kW}$ VRB is used as the storage battery. Considering the voltage level of the battery, a two-stage topology of the PCS, which is composed of a bidirectional DC-DC converter and a three-phase inverter, is used as shown in Figure 1. This designed topology of the PCS can realize the flexible control of the VRB, as it can be controlled by the DC-DC converter and the inverter. In addition, its size is relatively small as no power transformer is needed.

In this designed VRB ESS, a phase-shifted full bridge dc-dc converter is used as the bidirectional DC-DC converter and its design is introduced in Section 4, associated with the control strategy of the VRB ESS.

\section{Vanadium Redox Flow Battery}

\subsection{Structure and Operating Principles of the VRB}

A VRB, as an electrochemical cell, is divided into two compartments. One is the positive and negative tanks containing the electrolyte, and the other is the pump and piping for circulating the electrolyte from the tanks to the cell. The vanadium ion $\mathrm{VO}^{2+}$ is in the positive electrode and $\mathrm{V}^{3+}$ is in the negative electrode. They transform themselves to $\mathrm{VO}_{2}{ }^{+}$and $\mathrm{V}^{2+}$, respectively, by charging the VRB. At the same time, $\mathrm{H}^{+}$moves from the positive electrode to the negative, through the ion-exchange membrane. The discharging process of the VRB follows a similar process. Figure 2 shows the structure and operating principles of the VRB [14].

In Figure 2, the potential of the individual cells is given by the Nernst equation and depends on the vanadium species concentrations and the proton concentrations [15]:

$$
E=E^{\Theta}+\frac{R T}{F} \ln \left\{\left(\frac{\mathrm{c}_{V O_{2}+} \cdot \mathrm{c}^{2} H^{+}}{\mathrm{c}_{V O^{2+}}}\right)\left(\frac{\mathrm{c}_{V^{2+}}}{\mathrm{c}_{V^{3+}}}\right)\right\}[V]
$$

where $E^{\Theta}$ is the formal potential, which is set as $1.255 \mathrm{~V} ; T$ is the stack temperature; $R$ is the universal gas constant $8.314 \mathrm{~J} \cdot \mathrm{K}^{-1} \cdot \mathrm{mol}^{-1}$; and $F$ is Faraday's constant $96,485.3399 \mathrm{~mol}^{-1}$. $c$ is the concentration of ions and it depends on the value of the SOC: 


$$
\frac{\mathrm{c}_{V^{2+}}}{\mathrm{c}_{V^{3+}}}=\frac{\mathrm{c}_{V O_{2}+}}{\mathrm{c}_{V O^{2+}}}=\frac{S O C}{1-S O C}, \mathrm{c}_{H^{+}}=\mathrm{c}_{H^{+}(o)}+S O C
$$

where $\mathrm{c}_{H^{+}(o)}$ is the initial concentration of $\mathrm{H}^{+}$. The sum of the equilibrium potential $E$ of the individual cells presents the stack potential.

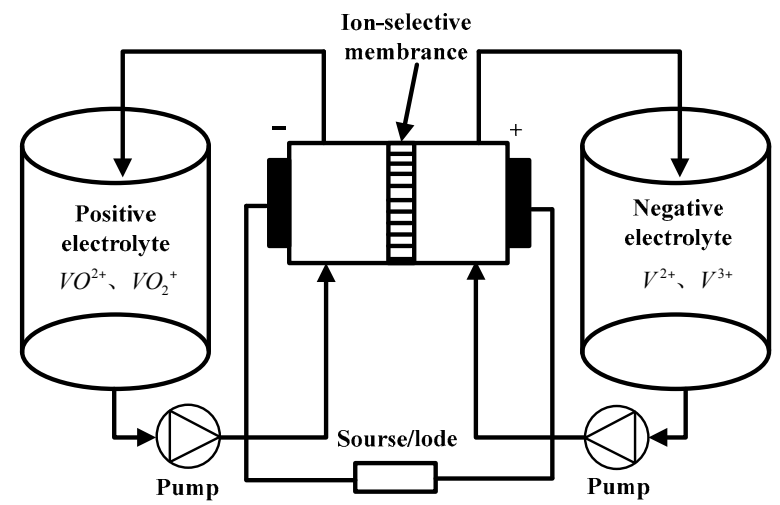

Figure 2. Structure and operating principles of the VRB.

When a net current is flowing through the stack, the equilibrium conditions are not met and the stack voltage $U_{\text {stack }}$ is then given by the difference between the equilibrium potential $U_{\text {eq }}$ and the internal losses $U_{\text {loss }}[2,15]$.

$$
U_{\text {stack }}=U_{\mathrm{eq}}-U_{\text {loss }}=n E-R_{\text {eq, chargr } / \text { discharge }} I
$$

where $n$ is the number of cells in the stack, $R_{\text {eq,chargr/discharge }}$ is the equivalent charge resistance of the VRB under charging or discharging, and $I$ is the charging or discharging current. In Equation (3), E can be calculated by Equation (1), in which the concentration $c$ is calculated by the SOC in Equation (2).

\subsection{Simplified Method for SOC Estimation}

The SOC of the VRB is an important parameter reflecting the residual capacity of the VRB and it is the key parameter for regulating the operating states of a VRB ESS. The traditional method for SOC estimation is based on the equivalent circuit of the VRB, which is shown in Figure 3 [16,17]. In Figure 3, the stack voltage $U_{\text {stack }}$ is imitated by a voltage-controlled source, which is influenced by the value of the SOC and the cell voltage of the VRB, as shown in Equation (3).

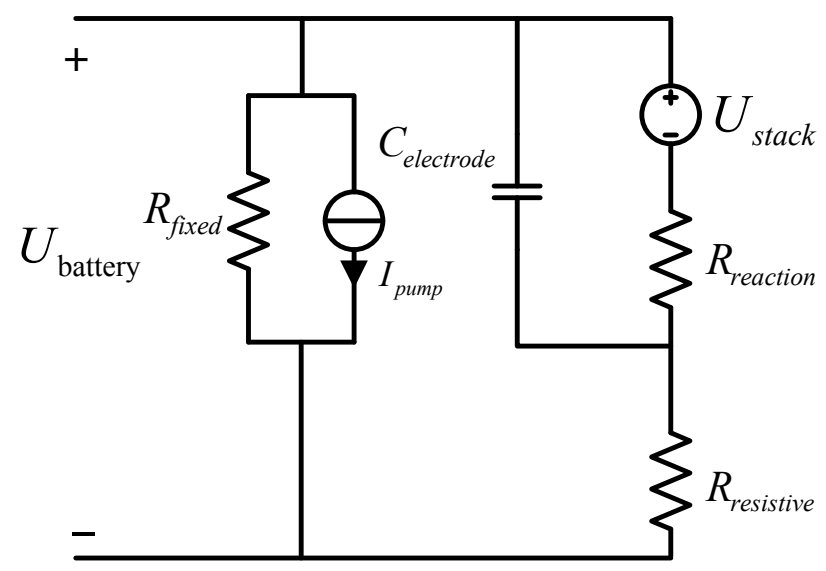

Figure 3. Equivalent Circuit of the VRB. 
Generally, the system state of charge can be defined as Equation (4):

$$
S O C=\frac{E_{\text {current }}}{E_{\text {capacity }}}
$$

In line with Equation (4) and the equivalent circuit of the VRB, Equation (5) can be acquired:

$$
\triangle S O C=\frac{\Delta E}{E_{\text {capacity }}}=\frac{P_{\text {stack }} \cdot T_{\text {step }}}{E_{\text {capacity }}}=\frac{U_{\text {stack }} \cdot I_{\text {stack }} \cdot T_{\text {step }}}{P_{\text {rating }} \cdot T_{\text {rating }}}
$$

Accordingly, the value of the SOC can be calculated by Equation (6):

$$
S O C=S O C_{o}+\int \frac{U_{\text {stack }} \cdot I_{\text {stack }}}{P_{\text {rating }} \cdot T_{\text {rating }}} d t
$$

In [14], the SOC estimation method based on Equation (6) is proposed and this VRB SOC estimation method is named the traditional SOC estimation method in this paper. It should be noted that this traditional SOC estimation method is very complex to implement, considering the required integration operation in Equation (6). Besides, the stack current $I_{\text {stack }}$ is difficult to accurately measure.

In line with (3), the stack voltage $U_{\text {stack }}$ can be calculated and the corresponding parameters are given in Table 1 . Then, the terminal voltage $U_{\text {battery }}$ of the $5 \mathrm{~kW}$ VRB under a constant current can be caught by the simulation of the VRB equivalent circuit, and the parameters of the VRB equivalent circuit are given in $[15,16]$. Figure 4 shows the curves of $U_{\text {battery }}$ and $U_{\text {stack }}$ of the $5 \mathrm{~kW}$ VRB in pace with the SOC under a constant charging current of $80 \mathrm{~A}$.

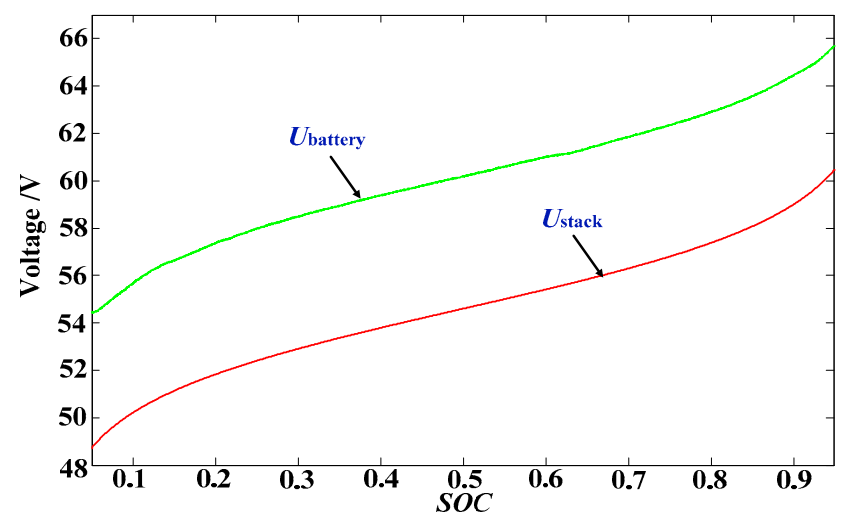

Figure 4. Voltage curves of the VRB under a charging current of $80 \mathrm{~A}$.

As can be seen from Figure 4 , the curves of $U_{\text {stack }}$ and $U_{\text {battery }}$ are approximately parallel, and the stack voltage $U_{\text {stack }}$ increases, along with the increase of the charging current $I_{\text {battery }}$. Hence, the value of the stack voltage $U_{\text {stack }}$ under charging can be approximated as Equation (7):

$$
U_{\text {stack,charge }}=U_{\text {battery,charge }}-I_{\text {battery }} \cdot R_{\text {charge }}
$$

where $R_{\text {charge }}$ is the charge resistance of the VRB under charging. Similarly, the stack voltage $U_{\text {stack }}$ under discharging can be approximated as (8):

$$
U_{\text {stack, discharge }}=U_{\text {battery,discharge }}+I_{\text {battery }} \cdot R_{\text {discharge }}
$$

where $R_{\text {discharge }}$ corresponds to the discharge resistance of the VRB under discharging. According to Equations (7) and (8) and Figure 5, $R_{\text {charge }}$ and $R_{\text {discharge }}$ are set at the same value, $0.0713 \Omega$, for the $5 \mathrm{~kW}$ VRB in this paper. 
In Figure 3, ignoring the impact of $R_{\text {fixed }}$ and $I_{\text {pump }}$, the stack current $I_{\text {stack }}$ of the VRB can be approximated as $I_{\text {battery }}$. As a result, the traditional VRB SOC estimation method based on (6) can be simplified and the stack voltage $U_{\text {stack }}$ can be calculated by Equations (7) and (8). Moreover, the stack current $I_{\text {stack }}$ is approximated by $I_{\text {battery }}$.

\subsection{Proposed SOC Estimation Method}

In this section, a simple and effective SOC estimation method is proposed. According to Equation (3), the curves of the stack voltage $U_{\text {stack }}$ of the $5 \mathrm{~kW}$ VRB in pace with the SOC under a constant charging and discharging current can be acquired. Therefore, the surface charts of the stack voltage $U_{\text {stack, }}$, terminal current $I_{\text {battery, }}$ and SOC under charging and discharging, can be fitted, shown in Figures 5 and 6, respectively.

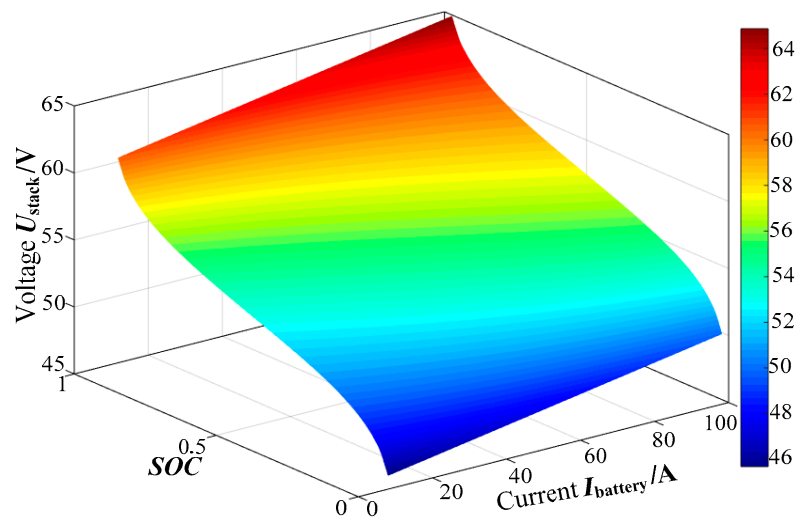

Figure 5. Surface charts of the stack voltage under charging.

It can be seen from Figures 5 and 6 that the stack voltage $U_{\text {stack }}$ increases with the increase of the terminal current $I_{\text {battery }}$ and the value of the SOC. When the terminal current $I_{\text {battery }}$ is determined, the value of the SOC under charging and discharging can be rapidly calculated, based on the value of the stack voltage $U_{\text {stack }}$ and the surface charts of Figures 5 and 6, respectively. In addition, the stack voltage $U_{\text {stack }}$ under charging and discharging can be estimated by (7) and (8), respectively. Namely, the value of the SOC can only be estimated by the value of the terminal current $I_{\text {battery }}$ and terminal voltage $U_{\text {battery }}$, which can be accurately measured. This SOC estimation method aforementioned is the proposed SOC estimation method in this paper. This proposed SOC estimation method ignores the balance of the two half-cells and is very simple to implement. Further simulations in Section 5 will illustrate the effectiveness of this proposed SOC estimation method.

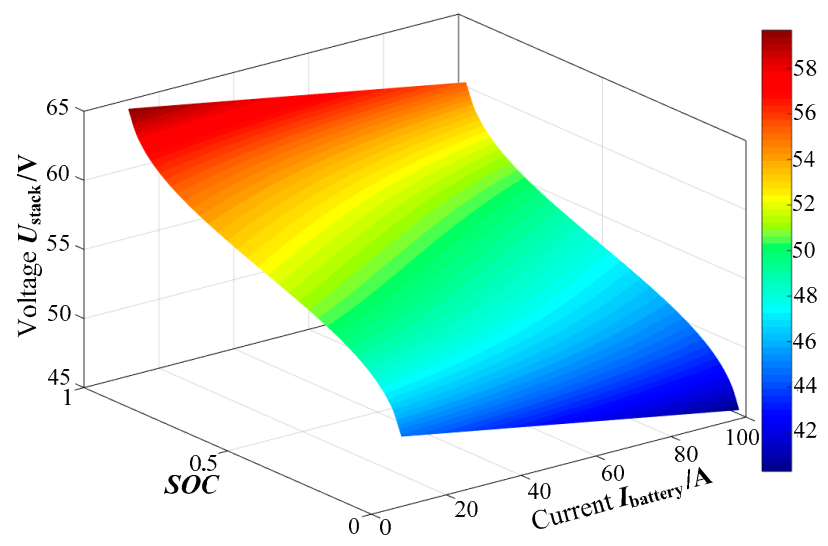

Figure 6. Surface charts of the stack voltage under discharging. 
The simulation parameters of the $5 \mathrm{~kW}$ VRB used in Figures 4-6 are shown in Table 1.

Table 1. Parameters of the $5 \mathrm{~kW}$ VRB.

\begin{tabular}{cc}
\hline Name & Value \\
\hline number of cells $N_{\text {cell }}$ & 39 \\
$R_{\text {eq, charge }} / \Omega$ & 0.047 \\
$R_{\text {eq, discharge }} / \Omega$ & 0.049 \\
electrolyte flowrate $Q /\left(\mathrm{L} \cdot \mathrm{s}^{-1}\right)$ & 2 \\
initial concentration of $\mathrm{H}^{+} /\left(\mathrm{mol} \cdot \mathrm{L}^{-1}\right)$ & 6 \\
electrolyte vanadium concentration $/\left(\mathrm{mol} \cdot \mathrm{L}^{-1}\right)$ & 2 \\
tank size $V_{t k} / \mathrm{L}$ & 260 \\
initial concentration of vanadium $/\left(\mathrm{mol} \cdot \mathrm{L}^{-1}\right)$ & 1 \\
\hline
\end{tabular}

\subsection{Equivalent of $V R B$}

In Figure 1, the VRB should be modeled for the control parameters design of an energy storage system. The model of the VRB based on Figure 3 is very complex and this model is not suitable for the modeling of an energy storage system. Namely, the model of the VRB should be simplified.

In accordance with Equation (7) and Figure 5, the equivalent resistance $R_{\mathrm{eq}}$ of the VRB $\left(R_{\text {eq }}=U_{\text {battery }} / I_{\text {battery }}\right)$ under a charging state can be acquired, as shown in Figure 7.

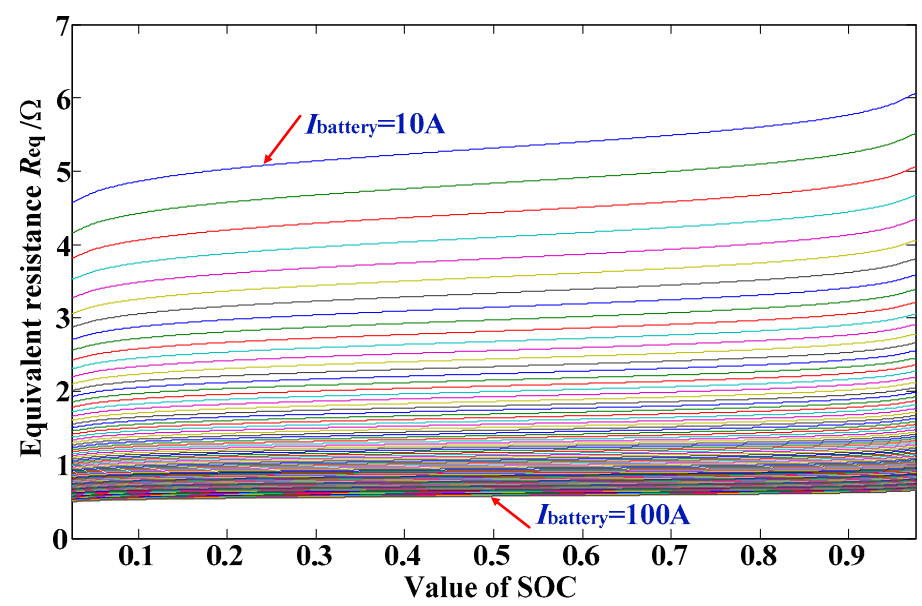

Figure 7. The equivalent resistance $R_{\mathrm{eq}}$ of the VRB under a charging state.

As can be seen from Figure $7, R_{\text {eq }}$ varies substantially with the SOC and current $I_{\text {battery }}$ under charging, which cannot be modeled as a fixed component. In this paper, the VRB energy storage system was designed under a constant charging current and constant charging power. The VRB should be considered in the worst case scenario, namely, when $R_{\mathrm{eq}}$ is selected as the minimum value. As an example, under a constant charging current of $80 \mathrm{~A}, R_{\mathrm{eq}}$ is considered as the minimum value $1 \Omega$ for the modeling of an energy storage system.

On the other hand, the VRB is modeled as a variable voltage source $U_{\text {eq }}$ under discharging in a VRB energy storage system. The variable amplitude $U_{\text {eq }}$ can be ascertained by Figure 6 and Equation (8). As an example, under a constant discharging current of $80 \mathrm{~A}, U_{\text {eq }}$ varies from $41.285 \mathrm{~V}$ to $56.251 \mathrm{~V}$. In this state, the VRB is modeled as a voltage source with a constant voltage of $41.285 \mathrm{~V}$, considering the worst case scenario (the SOC is considered as the minimum value, 0.025 ).

According to this simplified equivalent model of the VRB under charging and discharging, a VRB ESS was modeled and the control parameters of the ESS were reasonably designed in Section 4. 


\section{Design of an Energy Storage System}

\subsection{Structure of an Energy Storage System}

In a VRB ESS, a bi-directional DC-DC converter is required to raise the terminal voltage of the VRB and to achieve flexible control of the battery. In this paper, the phase-shifted full bridge dc-dc converter is used as the bi-directional DC-DC converter, to overcome the drawback of the low terminal voltage of the VRB, as shown in Figure 8.

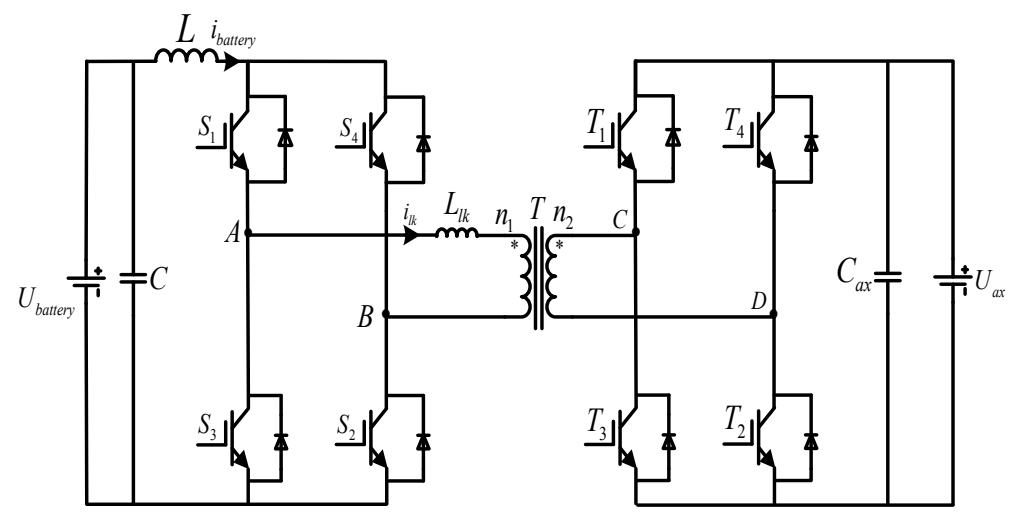

Figure 8. Bi-directional DC-DC converter in the ESS.

In Figure $8, T$ is a high frequency transformer which matches the voltage $U_{\text {battery }}$ and $U_{\mathrm{ax}}, L_{\mathrm{lk}}$ is the leakage inductance, and $\mathrm{L}$ is the output filter inductance.

When the VRB is charged, the phase-shifted full-bridge converter works in a buck state, by driving the switches $T_{1} \sim T_{4}$. On the other hand, when the VRB is discharged, the phase-shifted full-bridge converter works in a boost state, by driving the switches $S_{1} \sim S_{4}$. Hence, the bidirectional power flowing between the VRB and the AC grid is realized.

\subsection{Control Strategy of Energy Storage System}

The VRB ESS is mainly comprised of an on-grid mode and off-grid mode. In the on-grid mode, the VRB is discharged and supplies its chemical energy to the AC grid. In the off-grid mode, the VRB is used for storing the excess energy of the AC grid, which can be generated by renewable energy such as photovoltaic or wind power.

Figure 9 shows the control diagram of the bidirectional DC-DC converter, in which the VRB is charged and discharged under a constant current or power. Figure 10 shows the control strategy of the three-phase grid-connected inverter, in which the control strategy of the outer current loop and inner voltage loop were likely used. The phase of the grid connected current is controlled, remaining consistent with the phase of the grid voltage $[30,31]$.

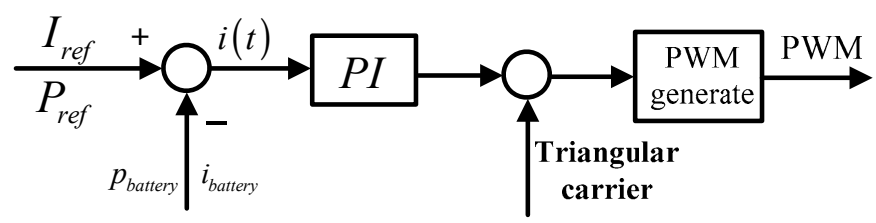

Figure 9. Control diagram of the bidirectional DC-DC converter. 


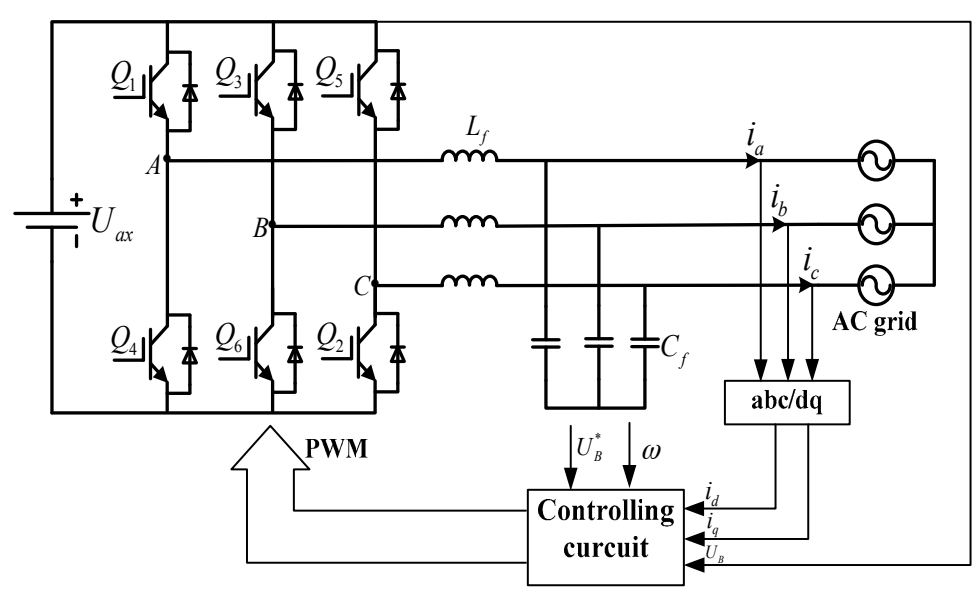

Figure 10. Control strategy of the three phase grid-connected inverter.

\subsection{Parameters Design of Controller}

In line with the model of the VRB and the control strategy of the ESS, the modeling of the VRB ESS can be analyzed.

The phase-shifted full-bridge DC-DC converter can be evolved from the Buck-Boost circuit, and its small-signal equivalent circuit has been shown in [32,33]. In a buck state, the VRB is modeled as a resistance $R_{\text {eq }}$ in the worst case. The transfer function of the output current $I_{\text {battery }}$ in pace with the duty ratio $d$ in the case of the continuous current mode is:

$$
G_{\mathrm{id}}(s)=\frac{n U_{\mathrm{ax}} \cdot\left[s C\left(\frac{R_{\mathrm{c}}}{R_{\mathrm{eq}}}+1\right)+\frac{1}{R_{\mathrm{eq}}}\right]}{L C\left(\frac{R_{\mathrm{c}}}{R_{\mathrm{eq}}}+1\right) s^{2}+\left[C R_{\mathrm{d}}\left(\frac{R_{\mathrm{c}}}{R_{\mathrm{eq}}}+1\right)+C R_{\mathrm{c}}+\frac{L}{R_{\mathrm{eq}}}\right] s+\left(\frac{R_{\mathrm{d}}}{R_{\mathrm{eq}}}+1\right)}
$$

where $R_{\mathrm{c}}$ is the resistance of capacitor $C$ and resistance $R_{\mathrm{d}}=4 n^{2} L_{\mathrm{lk}} f_{\mathrm{s}} . n$ is the turns ratio of the high frequency transformer $T$. The parameters of the ESS are presented in Table 2. Under an $80 \mathrm{~A}$ charging current, $R_{\mathrm{eq}}$ is considered as the minimum value $1 \Omega$ and the corresponding parameters of PI in Figure 10 can be designed, as shown in Figure 11.

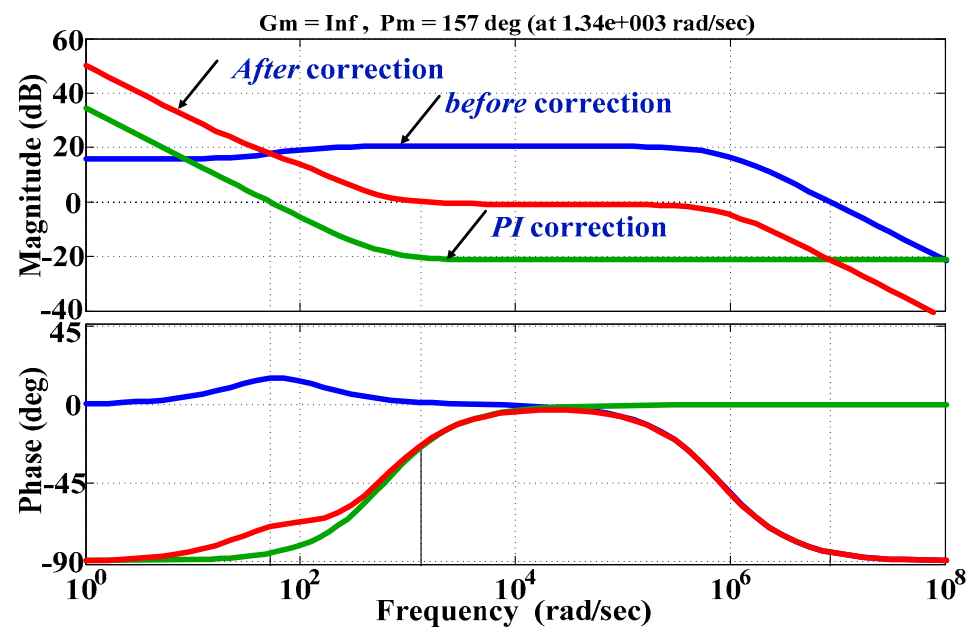

Figure 11. Mode of the DC-DC converter in a buck state.

In a boost state, the VRB is modeled as a voltage source with a constant voltage, and the parameters of the PI can be designed analogously. Besides, the design of a three-phase grid-connected inverter can be carried out by the small-signal modeling method [34], which is omitted as a space limitation. 
Table 2. Parameters of the designed bidirectional ESS for the VRB.

\begin{tabular}{cc}
\hline Name & Value \\
\hline inductance $L_{f} / \mu \mathrm{H}$ & 200 \\
capacitor $C_{f} / \mu \mathrm{F}$ & 100 \\
turns ratio $n$ of Transformer $T$ & $1: 8.35$ \\
leakage inductance $L_{\mathrm{lk}} / \mu \mathrm{H}$ & 25 \\
Switching frequency $f_{s} / \mathrm{kHz}$ & 5 \\
filter inductance $L / \mu \mathrm{H}$ & 80 \\
capacitor $C / \mu \mathrm{F}$ & 20 \\
Resistance of capacitance $R_{\mathrm{c}} / \Omega$ & 0.2 \\
\hline
\end{tabular}

\section{Simulation}

\subsection{Simulation Model of the VRB}

According to the equivalent circuit in Figure 3 and the parameters of the $5 \mathrm{~kW}$ VRB ESS, the corresponding simulation is set up by Simulink, to illustrate the proper design of the VRB ESS and the proposed SOC estimation method.

In simulation, the calculated VRB parameters are based on estimating losses of $21 \%$ in the worse case operating scenario, for a minimum voltage of $42 \mathrm{~V}$ and a current of $112 \mathrm{~A}$ [14]. Internal losses of the VRB account for $15 \%$, in which the reaction loss $P_{\text {reaction }}$ is $9 \%$ and the resistive loss $P_{\text {resistive }}$ is $6 \%$. The parasitic loss of the VRB accounts for $6 \%$, in which the fixed loss $P_{\text {fixed }}$ is $2 \%$ and the pump loss $P_{\text {pump }}$ is $4 \%$. The parameters of the $5 \mathrm{~kW}$ VRB are calculated as follows:

$$
\begin{gathered}
P_{\text {stack }}=\frac{5000}{1-0.21}=6329.11(\mathrm{~W}) \\
R_{\text {fixed }}=\frac{42^{2}}{P_{\text {fixed }}}=\frac{42^{2}}{6329.11 \times 2 \%}=13.936(\Omega) \\
P_{\text {parasitic }}=P_{\text {fixed }}+k\left(\frac{I_{\text {stack }}}{S O C}\right), k=42.5 \\
R_{\text {reaction }}=\frac{P_{\text {reaction }}}{I_{\text {stack }}^{2}}=\frac{569.62}{112^{2}} \approx 0.045(\Omega) \\
R_{\text {resistive }}=\frac{P_{\text {resistive }}}{I_{\text {stack }}^{2}}=\frac{379.75}{112^{2}} \approx 0.030(\Omega)
\end{gathered}
$$

\subsection{Simulation Results}

Based on the designed control parameters in the VRB ESS, the simulation results are shown in Figures 12-17, where Figures 12-14 show the simulation results under a charging and discharging current of $80 \mathrm{~A}$.

In Figure 12, the quantitative deviation of the current $I_{\text {battery }}$ and $I_{\text {stack }}$ is less than $5 \mathrm{~A}$. Therefore, the current $I_{\text {battery }}$ can be used to approximate $I_{\text {stack }}$ in practice. Besides, the curves of $U_{\text {stack }}$ and $U_{\text {battery }}$ under charging or discharging are approximately parallel.

In Figure 13, the efficiency of the VRB varies from 0.8 to 0.85 , and the efficiency of the VRB reaches its maximum value when the SOC is 0.975 . In addition, the efficiency of the VRB under a constant charging current of $80 \mathrm{~A}$ is higher than the efficiency of the VRB under a constant discharging current of $80 \mathrm{~A}$. This is because more energy is consumed when the VRB operates in a discharging state. 


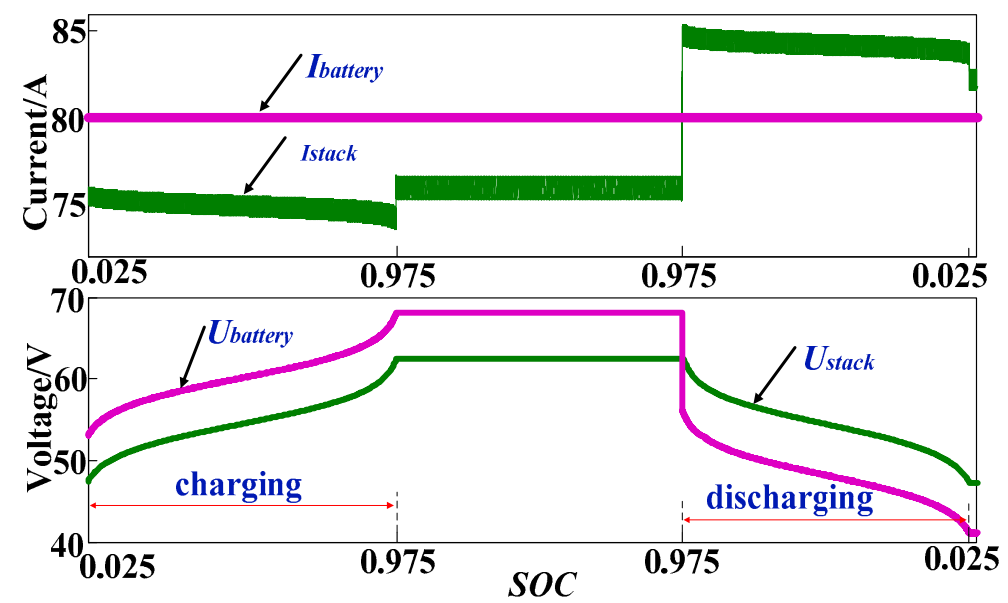

Figure 12. Current and voltage of the VRB under a charging and discharging current of $80 \mathrm{~A}$.

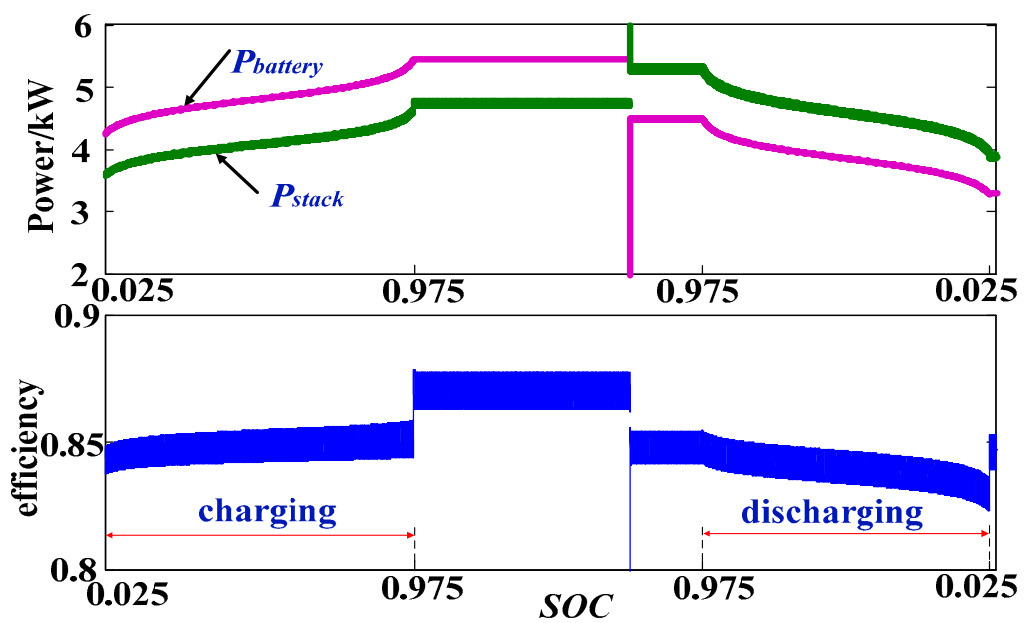

Figure 13. Power and efficiency of the VRB under a charging and discharging current of $80 \mathrm{~A}$.

In Figure 14, the actual value of the SOC was obtained by Equation (4). As can be seen from Figure 14, the proposed SOC estimation method is very effective, as the estimation value of the SOC is very close to the actual value of the SOC. Besides, the charging time is longer than the discharging time, as the charging time is about $5 \mathrm{~h}$ and the discharging time is about $4 \mathrm{~h}$. This is because the stack power in a discharging state is more expended.

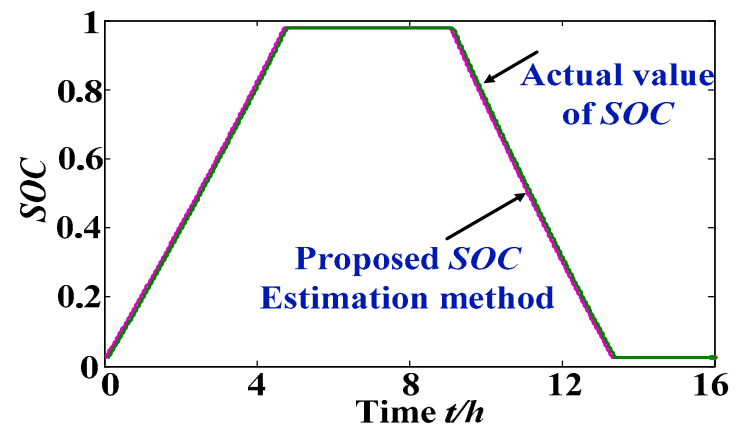

Figure 14. SOC of the VRB under a charging and discharging current of $80 \mathrm{~A}$. 
Similarly, Figures 15-17 show the simulation results under a charging and discharging power of $5 \mathrm{~kW}$.

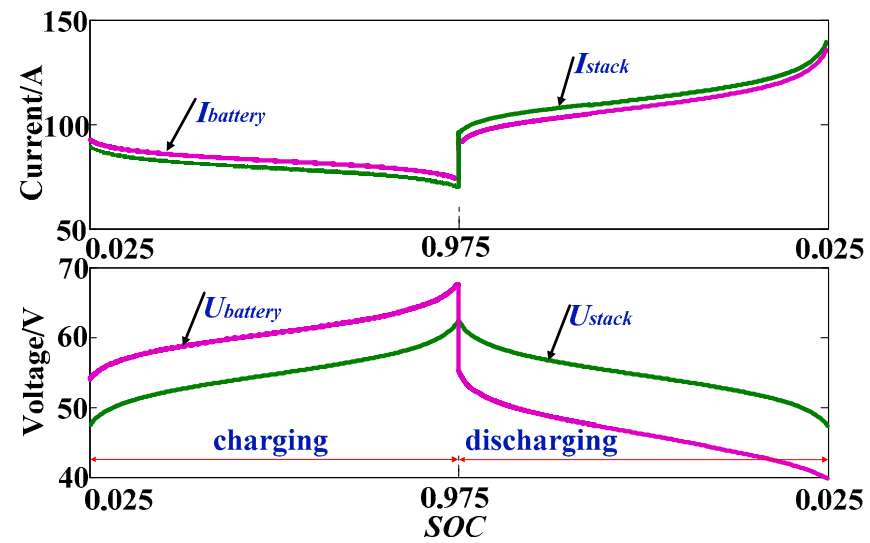

Figure 15. Current and voltage of the VRB under a charging and discharging power of $5 \mathrm{~kW}$.



Figure 16. Power of the VRB under a charging and discharging power of $5 \mathrm{~kW}$.

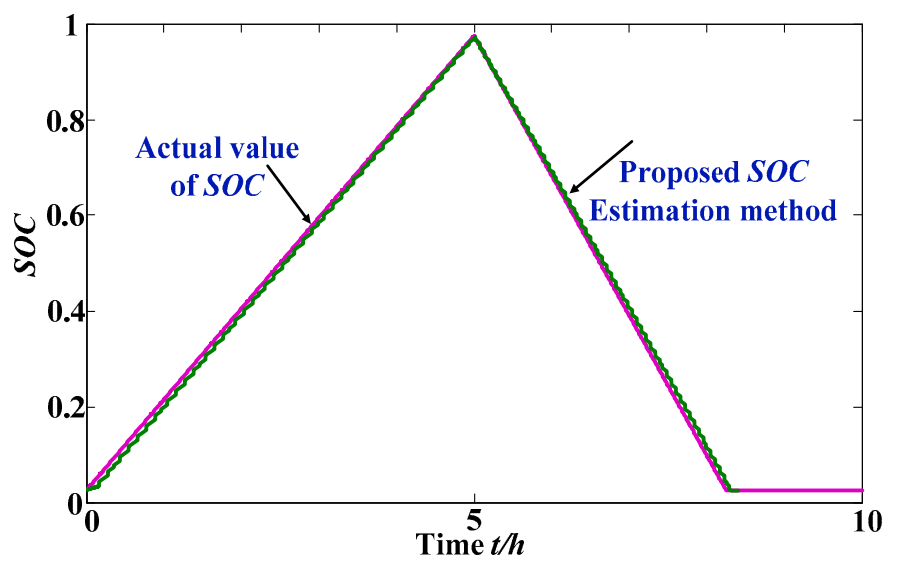

Figure 17. SOC of the VRB under a charging and discharging power of $5 \mathrm{~kW}$.

In Figure 15, the quantitative deviation of the current $I_{\text {battery }}$ and $I_{\text {stack }}$ is less than $5 \mathrm{~A}$, which again verifies that the stack current $I_{\text {stack }}$ of the VRB can be approximated as $I_{\text {battery }}$. From Figure 16, the efficiency of the VRB under a constant charging power of $5 \mathrm{~kW}$ is about 0.85 and the efficiency of the VRB under a constant discharging power of $5 \mathrm{~kW}$ is about 0.8 . The efficiency of the VRB reaches its 
maximum value when the SOC is 0.975 . In addition, the efficiency of the VRB increases in pace with the increase of the SOC, as shown in Figures 13 and 16.

In Figure 17, the charging time of the VRB under $5 \mathrm{~kW}$ power is about $5 \mathrm{~h}$, and the discharging time of the VRB under $5 \mathrm{~kW}$ power is about $3.25 \mathrm{~h}$. Compared with Figure 14, the error between the estimation value of the SOC and the actual value of the SOC is much bigger, which is mainly due to the variability of current $I_{\text {battery }}$ under a constant charging or discharging power of $5 \mathrm{~kW}$. However, this error is still very small, which again verifies the rationality and efficiency of the proposed SOC estimation method for a VRB ESS.

Moreover, the curves of the charging and discharging current $I_{\text {battery }}$ in Figure 12 and the curves of the charging and discharging power $P_{\text {battery }}$ in Figure 16 demonstrate a fast response, strong adaptation, and high steady precision, which reasonably verify the proper control parameters design of the VRB ESS.

\section{Conclusions}

DGs connected to a distribution system could critically cause some security risks for distribution systems. Considering the low terminal voltage of a VRB, this paper firstly designed a two-stage topology of a VRB energy storage system, in which a phase-shifted full bridge dc-dc converter was used and the bidirectional power flowing between the energy storage battery and the AC grid was achieved. Following this, according to the operational characteristics of the VRB in this proposed topology of a VRB ESS, the model of the VRB was simplified and the control parameters of the ESS were designed.

For effectively estimating the SOC of the VRB, a traditional method for SOC estimation was simplified, and a simple and effective SOC estimation method was proposed in this paper. Finally, the feasibility and effectiveness of the proposed SOC estimation method were verified by the designed VRB ESS, and the test results demonstrated that this proposed SOC estimation method is reasonable for indicating the SOC of a VRB, and that the design of the VRB ESS is suitable for VRB applications.

Acknowledgments: This work was supported by The National Key Technology R\&D Program of China (2013BAA02B01) and the Qinghai Province Key Laboratory of Photovoltaic Grid Connected Power Generation Technology (2014-Z-Y34A).

Author Contributions: Qingwu Gong proposed the concrete ideas of the proposed optimization method. Jiazhi Lei performed the simulations and wrote the manuscript.

Conflicts of Interest: The authors declare no conflict of interest.

\section{References}

1. Qiu, X.; Crow, M.L.; Elmore, A.C. A balance-of-plant vanadium redox battery system model. IEEE Trans. Sustain. Energy 2015, 6, 1-8. [CrossRef]

2. Díaz, A.; Ramos-Real, F.; Marrero, G.; Perez, Y. Impact of electric vehicles as distributed energy storage in isolated systems: The case of tenerife. Sustainability 2015, 7, 15152-15178. [CrossRef]

3. Williams, B.R.; Hennessy, T. Energy oasis [vanadium redox battery system in power distribution application]. Power Eng. 2005, 19, 28-31. [CrossRef]

4. Li, L.; Huang, Z.; Li, H.; Lu, H. A high-efficiency voltage equalization scheme for supercapacitor energy storage system in renewable generation applications. Sustainability 2016, 8, 548. [CrossRef]

5. Azib, T.; Bethoux, O.; Remy, G.; Marchand, C. An innovative control strategy of a single converter for hybrid fuel cell/supercapacitor power source. IEEE Trans. Ind. Electron. 2011, 57, 4024-4031. [CrossRef]

6. Wu, J.C.; Wang, Y.H. Three-phase to single-phase power-conversion system. IEEE Trans. Power Electron. 2011, 26, 453-461. [CrossRef]

7. Xia, T.; He, L.; An, N.; Li, M.; Li, X. Electromechanical transient modeling research of energy storage system based on power system security and stability analysis. In Proceedings of the IEEE International Conference on Power System Technology, Chengdu, China, 20-22 October 2014; IEEE Press: New York, NY, USA, 2014; pp. 221-226. 
8. Ni, L.; Patterson, D.J.; Hudgins, J.L. A high power, current sensorless, bi-directional, 16-phase interleaved, DC-DC converter for hybrid vehicle application. In Proceedings of the IEEE Energy Conversion Congress and Exposition, Raleigh, NC, USA, 12-16 September 2010; IEEE Press: New York, NY, USA, 2010; pp. 1141-1151.

9. Jin, K.; Ruan, X.; Yang, M.; Xu, M. Power management for fuel-cell power system cold start. IEEE Trans. Power Electron. 2009, 24, 2391-2395. [CrossRef]

10. Li, X.; Zhang, W.; Li, H.; Xie, R. Design and control of bi-directional DC/DC converter for $30 \mathrm{~kW}$ fuel cell power system. In Proceedings of the IEEE 8th International Conference on Power Electronics and ECCE Asia (ICPE \& ECCE), Jeju, Korea, 30 May-3 June 2011; IEEE Press: New York, NY, USA, 2011; pp. 1024-1030.

11. Sabate, J.A.; Vlatkovic, V.; Ridley, R.B.; Lee, F. Design considerations for high-voltage high-power full-bridge zero-voltage-switched PWM converter. In Proceedings of the IEEE Applied Power Electronics Conference and Exposition (APEC), Los Angeles, CA, USA, 11-16 March 1990; IEEE Press: New York, NY, USA, 1990; pp. 275-284.

12. Jeon, S.J.; Cho, G.H. A zero-voltage and zero-current switching full bridge dc-dc converter with transformer isolation. IEEE Trans. Power Electron. 2001, 16, 573-580. [CrossRef]

13. Schutten, M.J.; Torrey, D. Improved small-signal analysis for the phase-shifted pwm power converter. IEEE Trans. Power Electron. 2003, 18, 659-669. [CrossRef]

14. Barote, L.; Marinescu, C. A new control method for VRB SOC estimation in stand-alone wind energy systems. In Proceedings of the IEEE International Conference on Clean Electrical Power, Capri, Italy, 9-11 June 2009; IEEE Press: New York, NY, USA, 2009; pp. 253-257.

15. Blanc, C.; Rufer, A. Multiphysics and energetic modeling of a vanadium redox flow battery. In Proceedings of the IEEE International Conference on Sustainable Energy Technologies in Singapore, 24-27 November 2008; IEEE Press: New York, NY, USA, 2008; pp. 696-701.

16. Li, M.H.; Funaki, T.; Hikihara, T. A Study of Output Terminal Voltage Modeling for Redox Flow Battery Based on Charge and Discharge Experiments. In Proceedings of the Power Conversion Conference, Nagoya, Japan, 2-5 April 2007; IEEE Press: New York, NY, USA, 2007; pp. 221-225.

17. Barote, L.; Weissbach, R.; Teodorescu, R.; Marinescu, C.; Cirstea, M. Stand-alone wind system with Vanadium Redox Battery energy storage. In Proceedings of the IEEE International Conference on Optimization of Electrical and Electronic Equipment, Brasov, Romania, 22-24 May 2008; IEEE Press: New York, NY, USA, 2008; pp. 407-412.

18. Barote, L.; Marinescu, C.; Georgescu, M. VRB modeling for storage in stand-alone wind energy systems. In Proceedings of the IEEEBucharest PowerTechin, Bucharest, Romania, 28 June-2 July 2009; IEEE Press: New York, NY, USA, 2009; pp. 1-6.

19. Zhang, Y.; Zhao, J.; Wang, P.; Skyllas-Kazacos, M.; Xiong, B.; Badrinarayanan, R. A comprehensive equivalent circuit model of all-vanadium redox flow battery for power system analysis. J. Power Sources 2015, 290, 14-24. [CrossRef]

20. Tang, A.; Bao, J.; Skyllas-Kazacos, M. Studies on pressure losses and flow rate optimization in vanadium redox flow battery. J. Power Sources 2014, 248, 154-162. [CrossRef]

21. Lawder, M.T.; Suthar, B.; Northrop, P.W.C.; De, S.; Hoff, C.M.; Leitermann, O. Battery energy storage system (bess) and battery management system (bms) for grid-scale applications. Proc. IEEE 2014, 102, 1014-1030. [CrossRef]

22. Santhanagopalan, S.; White, R.E. State of charge estimation using an unscented filter for high power lithium ion cells. Int. J. Energy Res. 2010, 34, 152-163. [CrossRef]

23. Guggenberger, J.; Elmore, C.; Tichenor, J.; Crow, M. Performance prediction of a vanadium redox battery for use in portable, scalable microgrids. IEEE Trans. Smart Grid 2012, 3, 2109-2116. [CrossRef]

24. Nguyen, T.A.; Xin, Q.; Guggenberger, J.D.; Crow, M.L.; Elmore, A.C. Performance characterization for photovoltaic-vanadium redox battery microgrid systems. IEEE Trans. Sustain. Energy 2014, 5, 1379-1388. [CrossRef]

25. Corcuera, S.; Skyllaskazacos, M. State-of-charge monitoring and electrolyte rebalancing methods for the vanadium redox flow battery. Eur. Chem. Bull. 2012, 1, 511-519.

26. Gharavian, D.; Pardis, R.; Sheikhan, M. ZEBRA battery SOC estimation using pso-optimized hybrid neural model considering aging effect. IEICE Electron. Express 2012, 9, 1115-1121. [CrossRef]

27. Skyllas-Kazacos, M.; Kazacos, M. State of charge monitoring methods for vanadium redox flow battery control. J. Power Sources 2011, 196, 8822-8827. [CrossRef] 
28. Xiong, B.; Zhao, J.; Wei, Z.; Skyllas-Kazacos, M. Extended kalman filter method for state of charge estimation ofvanadium redox flow battery using thermal-dependent electrical model. J. Power Sources 2014, 262, 50-61. [CrossRef]

29. Ghazanfari, A.; Hamzeh, M.; Mokhtari, H.; Karimi, H.R. Active power management of multihybrid fuel cell/supercapacitor power conversion system in amedium voltage microgrid. IEEE Trans. Smart Grid 2012, 3, 1903-1910. [CrossRef]

30. Shen, H.; Zhang, Y.; Shi, Y.L.; Sun, L. Research on control strategy of three-phase grid-connected inverter under distorted and unbalanced voltage conditions. In Proceedings of the IEEE Transportation Electrification Asia-Pacific, Beijing, China, 31 August-3 September 2014; IEEE Press: New York, NY, USA, 2014; pp. 1-6.

31. Wu, Y.; Li, N.; Yao, Z.; Xue, Y.; Wu, D. Control strategy based on double coordinates for three-phase grid-connected inverters. In Proceedings of the International Power Electronics and Motion Control, Harbin, China, 2-5 June 2012; IEEE Press: New York, NY, USA, 2012; pp. 2272-2276.

32. Vlatković, V.; Sabaté, J.; Ridley, R.B.; Lee, F.C.; Cho, B.H. Small-signal analysis of the phase-shifted pwm converter. IEEE Trans. Power Electron. 1992, 7, 128-135. [CrossRef]

33. Hu, X.; Nan, G. The research of modeling and simulation for phase-shifted full-bridge ZVS DC/DC converter. In Proceedings of the IEEE International Conference on Intelligent Information Technology Application, Nanchang, China, 21-22 November 2009; IEEE Press: New York, NY, USA, 2009; pp. 549-552.

34. Liu, X.D.; Wu, J.; Liu, S.C.; Fang, W.; Liu, Y.F. A current control strategy of three-phase grid-connected inverter with LCL filter based on one-cycle control. In Proceedings of the 17th International Conference on Electrical Machines and Systems (ICEMS), Hangzhou, China, 22-25 October 2014; IEEE Press: New York, NY, USA, 2014; pp. 939-943.

(C) 2017 by the authors. Licensee MDPI, Basel, Switzerland. This article is an open access article distributed under the terms and conditions of the Creative Commons Attribution (CC BY) license (http://creativecommons.org/licenses/by/4.0/). 